\title{
Tư duy chiến lược về động lực phát triển kinh tế
}

\author{
Trần Đình Thiên \\ Viện Kinh tế Việt Nam \\ Viện Hàn lâm KHXH Việt Nam \\ Kỷ yêu Hội thảo khoa học Hoạch định chính sách kinh tế vĩ mô \\ Học viện Hành chính Quốc gia (NAPA) / Bộ Nội Vụ \\ Hà Nội, 10-8-2019
}




\title{
TƯ DUY CHIẾN LƯợC VỀ ĐộNG LỰC PHÁT TRIỂN KINH TẾ
}

\author{
PGS.TS. Trần Đình Thiên
}

Viện Kinh tế Việt Nam

Viện Hàn lâm KHXH Việt Nam

Tóm tắt:

Thay đổi phưong thức quản lý và cấu trúc sở hưu đã tạo động lục cho nền kinh tế Việt Nam gặt hái được nhũng thành tích rất tích cực sau 30 năm đổi mới. Tuy nhiên, nhìn sâu vào thực chất phát triển, đặc biệt là một số chỉ số phản ánh chất lượng tăng truơơng - phát triển thì dễ nhận thấy nền kinh tế nước ta hiện nay đang chứa đựng hàng loạt vấn đề nghiêm trọng. Đó chính là lý do nội tại buộc phải nghiên cứu lại vấn đề "động lực tăng trưởng và phát triển" một cách căn bản, có hệ thống và nghiêm túc. Từ nhận diện ra vấn đề, tác giả đã phân tích thực trạng phát huy động lục phát triển trong giai đoạn đổi mới vì̀a qua; chỉ ra bối cảnh mới, yêu cầu mới, tù đó đề xuất các giải pháp tăng cuờng động lực phát triển cho nền kinh tế Việt Nam trong giai đoạn tóit.

\section{Nhận diện vấn đề}

Nhìn tổng thể hơn 30 năm đổi mới vừa qua, thành tích tăng trưởng và phát triển kinh tế của nước ta là rất tích cực. Quan trọng nhất là việc thay đổi phương thức phát triển - từ kinh tế kế hoạch hóa tập trung bao cấp chuyển sang kinh tế thị trường - mở cửa, tạo ra một động lực phát triển mới mạnh mẽ, giúp nền kinh tế thoát khỏi tình trạng "mất động lực tăng trưởng" kéo dài nhiều năm trước.

Nền tảng tạo động lực mới là sự thay đổi cấu trúc sở hữu - nền kinh tế "độc tôn công hữu" (sở hữu nhà nước và sở hữu tập thể thống trị) được thay thế bằng nền kinh tế đa sở hữu (nhiều thành phần, chấp nhận kinh tế tư nhân). Việc thay đổi phương thức phát triển, chấp nhận cơ chế thị trường, chuyển sang quỹ đạo tăng trưởng và phát triển mới đã mang lại nhiều kết quả ngoạn mục: xóa đói giảm nghèo, tăng trưởng GDP, tăng trưởng xuất - nhập khẩu, thu hút đầu tư nước ngoài, dịch chuyển cơ cấu ngành, v.v.

"Xuất phát tù̀ một nước nghèo, lạc hạu, sản xuất hầu nhu không đáp ưng nhu cầu trong nuớc, sau gần 30 năm thực hiện công cuộc đổi móit, Việt Nam đã đạt được nhiều thành tưu quan trọng trong phát triển kinh tế. Tổng sản phẩm trong nuớc (GDP) luôn duy trì tăng trưởng khá với tốc độ tăng bình quân năm thời kỳ 1990-2014 đạt 6,9\%, đưa 
Việt Nam tù một quốc gia thuộc nhóm các nước nghèo nhất thế giới trở thành nước có thu nhập trung bình với GDP bình quân đầu ngwời năm 2014 đạt 2052 USD, gấp 21 lần mức bình quân năm 1990... Từ một quốc gia có GDP năm 1990 chỉ đạt khoảng 6,4 tỷ USD, xếp vị trí thứ 90 thế giới, sau gần 25 năm phát triển, quy mô kinh tế của Việt Nam đã cải thiện đáng kể với GDP năm 2014 đạt 186,2 tỷ USD, xếp vị trí 55 thế giới”.

(Kỷ yếu Hội thảo khoa học, Bộ Kế hoạch và Đầu tư, 2015: "Cải cách thể chế kinh tế Việt Nam để hội nhập và phát triển giai đoạn 2015-2035”')

Nhưng nhìn sâu vào thực chất phát triển, đặc biệt là một số chỉ số phản ánh chất lượng tăng trưởng - phát triển như sự thay đổi trình độ công nghệ hay trình độ cơ cấu kinh tế (thủ công hay cơ khí; lắp ráp gia công hay chế tạo; bắt chước hay sáng tạo công nghệ), dễ nhận thấy nền kinh tế nước ta hiện nay đang chưa đựng hàng loạt vấn đề nghiêm trọng: tăng trưởng không vững chắc, xu hướng suy giảm tốc độ tăng trưởng GDP, chất lượng và đẳng cấp phát triển kinh tế (trình độ công nghệ, chất lượng lao động, trình độ thể chế) chậm thay đổi, thực lực doanh nghiệp Việt Nam yếu, chậm được cải thiện, các điểm tắc nghẽn tăng trưởng và phát triển chậm được tháo gỡ, v.v. Mức độ nghiêm trọng còn rõ ràng hơn khi xem xét "tính có vấn đề" của thực lục doanh nghiệp Việt Nam tù̀ góc độ cạnh tranh - đua tranh quốc tế.

Từ thực trạng cơ bản đó, có thể nêu nhận định khái quát:

+ Các thành tích tăng trưởng và phát triển kinh tế được coi ngoạn mục trong giai đoạn vừa qua cơ bản gắn với việc khai thác các nguồn lục sẵn có (nguồn lục "tĩnh”) theo cách "tận khai” truyền thống (khai thác và xuất khẩu tài nguyên thô để bán là cơ sở chủ yếu của tăng trưởng), it dựa vào nhũng thay đổi cơ cấu. Ngay cả nỗ lực mở cửa - hội nhập để vươn ra thế giới, nhanh chóng thu hẹp khoảng cách tụt hậu với các nước đi trước cũng dựa chủ yếu vào nền tảng "tận khai" tài nguyên, lao động rẻ, kỹ năng thấp và đông đảo các doanh nghiệp nhỏ và siêu nhỏ yếu kém về năng lực.

+ Trong khi đó, tình trạng "có vấn đề" (nghiêm trọng) của sự phát triển lại bắt nguồn từ chỗ các động lực phát triển (nguồn lực "động”) của nền kinh tế không được phát huy, thậm chí bị suy giảm nhanh.

Đây chính là lý do nội tại buộc chúng ta phải nghiên cúu lại vấn đề “động lục tăng trưởng và phát triển" một cách căn bản, có hệ thống và nghiêm túc, giống như cách đây hơn 30 năm, vào thời điểm "đêm trước đổi mới”, khi vấn đề "động lực 
phát triển”, tình trạng "suy giảm động lực lao động” được đặt ra gay gắt, báo hiệu công cuộc đổi mới mang tính cách mạng (thực sự diễn ra từ Đại hội Đảng lần thứ VI năm 1986).

Tuy nhiên, hiện nay, sau hơn 30 năm đổi mới, khi tình thế phát triển của Việt Nam đã thay đổi căn bản - thế giới chuyển sang thời đại công nghệ cao (cách mạng công nghiệp 4.0), điều kiện phát triển thay đổi, cần tiếp cận đến vấn đề “động lực phát triển" ở một tầm thế khác: tìm kiếm những động lực mới, những phương thức phát huy động lực mới kết hợp với những động lực và phương thức truyền thống.

Đây chính là yêu cầu mà nghiên cứu này giải quyết.

\section{Thực trạng phát huy động lực phát triển trong giai đoạn đổi mới vừa qua.}

Công cuộc đổi mới kinh tế hơn 30 năm qua có nội dung cốt lõi là thay đổi phương thức phát triển - từ hệ thống thể chế - quan hệ sản xuất XHCN "truyền thống" với hai trục chính là i) chế độ sở hữu "độc tôn công hữu" (thực chất là độc tôn sở hữu nguồn lực) và ii) cơ chế kế hoạch hóa tập trung (cơ chế phân bổ các nguồn lực) sang thể chế thị trường với hai trục cốt lõi i) chế độ “đa sở hữu - nhiều thành phần” và ii) cơ chế cạnh tranh thị trường. Phương thức phát triển mới được xác lập đã giúp nền kinh tế đang bị kiệt quệ do khủng hoảng hồi sinh nhanh chóng, mang lại cho nó một động thái phát triển mới và những kết quả tăng trưởng và phát triển kinh tế ngoạn mục (Hình 1).

\section{Hình 1: Tăng trưởng GDP và Thu nhập bình quân đầu người (1984-2013)}

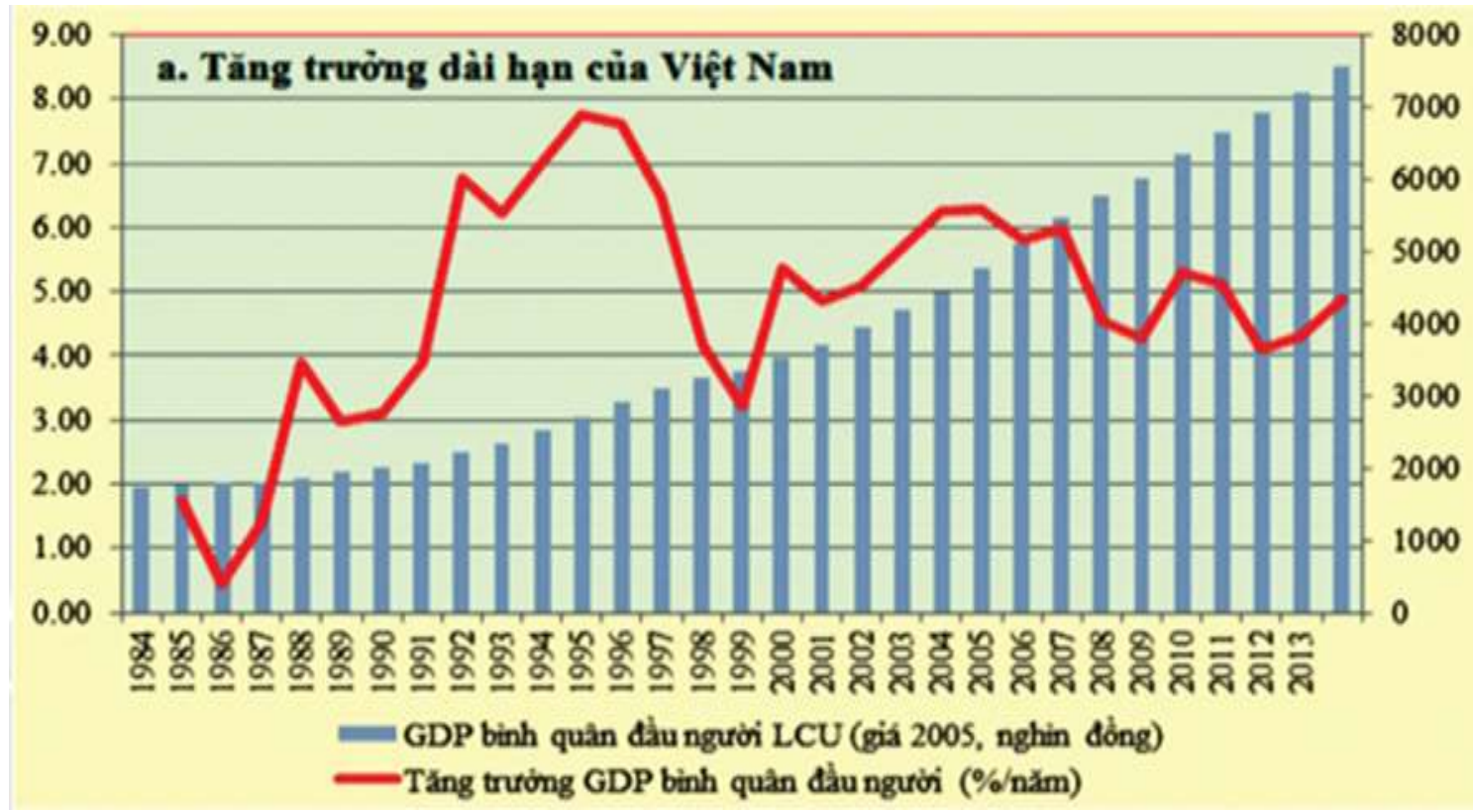


Tuy nhiên, song song với những thành tích "ngoạn mục" đó, trong nền kinh tế cũng xuất hiện những trở lực phát triển, làm triệt tiêu hoặc "chệch hướng" các động lực phát triển mới được xác lập và ngày càng trở nên khó khắc phục.

Sự phân tích dưới đây mổ xẻ xu thế "phản lực" này, những hậu quả và nguyên nhân của nó, với mục tiêu tìm kiếm các giải pháp khắc phục và những động lực phát triển mới.

\subsection{Thục trạng vận hành các động lục tăng trưởng, phát triển kinh tế}

Để nhận diện thực trạng vận hành các động lực tăng trưởng và phát triển kinh tế, trước tiên, hãy phân tích xu thế tăng trưởng và phát triển kinh tế ngắn hạn và dài hạn.

Đồ thị 2 cho thấy xu hướng suy giảm tốc độ tăng trưởng GDP giai đoạn 19912018 qua từng nhịp 10 năm: sau nhịp 10 năm đầu tiên, tốc độ tăng trưởng hàng năm của nhịp 10 năm thứ hai giảm $0,8 \%$ và của nhịp 10 năm thứ ba giảm $0,6 \%$. Xu hướng giảm tốc độ tăng trưởng GDP một cách "vững chắc" như vậy đi ngược lại mục tiêu ưu tiên cao nhất xuyên suốt cả giai đoạn là phấn đấu đạt "tốc độ tăng trưởng cao, năm sau cao hơn năm trước".

Hình 2: Tốc độ tăng truởng GDP bình quân hàng năm giai đoạn 1991-2018

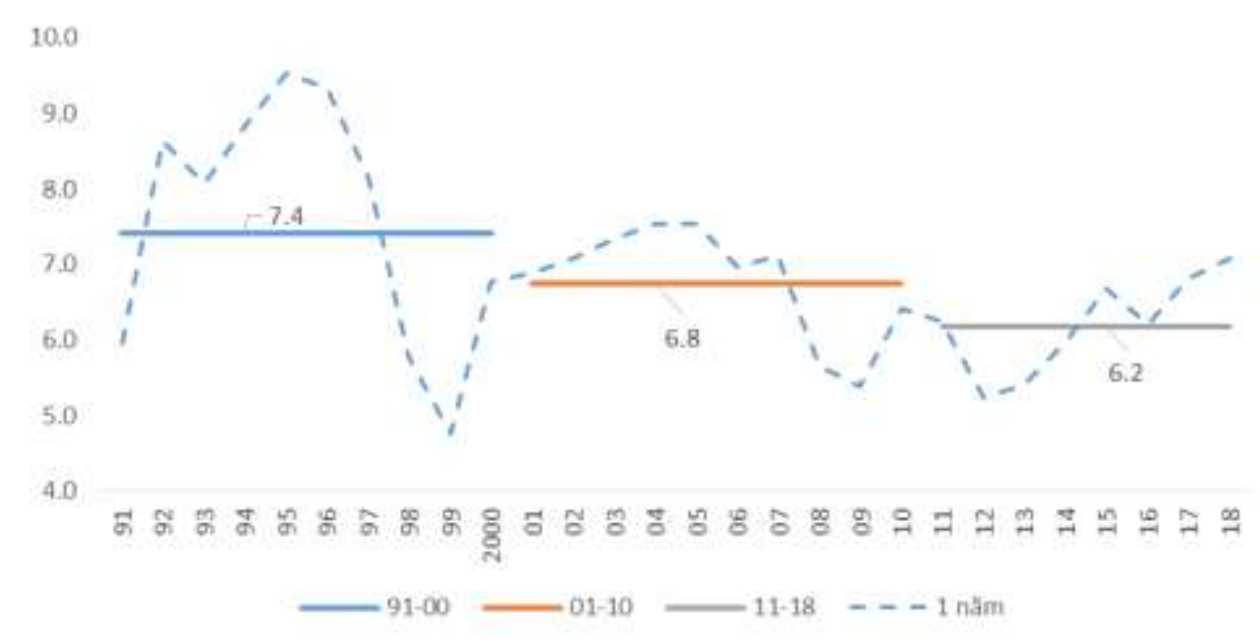

Nguồn: Tổng hợp tù̀ số liệu Niên giám Thống kê các năm 1992-2018 
Tại sao lại như vậy? Có phải nền kinh tế Việt Nam đã có quy mô lớn đến mức tốc độ tăng trưởng GDP có xu hướng giảm thấp so với giai đoạn quy mô còn nhỏ?

Còn một thực trạng tăng trưởng khác, phản ánh bản chất: xu thế tụt hậu phát triển của Việt Nam so với thế giới, nhất là với các nước trong khu vực.

Hình 3 cho thấy tình trạng tụt hậu xa hơn của Việt Nam so với các đối thủ cạnh tranh chủ yếu đã không còn là nguy cơ mà đã thành hiện thực. Thực tế đáng lo ngại này hàm ý rằng thành tích tăng truởng của Việt Nam chua đủ xuất sắc để rút ngắn, thu hẹp khoảng cách tụt hâu phát triển; rằng động lục tăng trưởng và phát triển của Việt Nam chua đủ mạnh để giúp nền kinh tế bưt lên, tiến vuợt và tiến kịp thế giới. Đây là vấn đề lớn đặt ra cho Việt Nam, trong bối cảnh đi sau, tham gia hội nhập quốc tế nhanh và sâu, khi cả thế giới chuyển nhanh sang thời đại công nghệ cao.

Nguyên nhân của tình trạng này không thể giải thích bằng tác động bên ngoài, hay ở các nguyên nhân ngẫu nhiên, ngắn hạn. Vấn đề mấu chốt là động lục tăng trưởng kinh tế của Việt Nam đã suy giảm liên tục sau giai đoạn khởi động đổi mới khá ngoạn mục.

Hình 3: Xu thế tụt hậu xa hơn: GDP/người của Việt Nam so với của các nền kinh tế trong khu vực

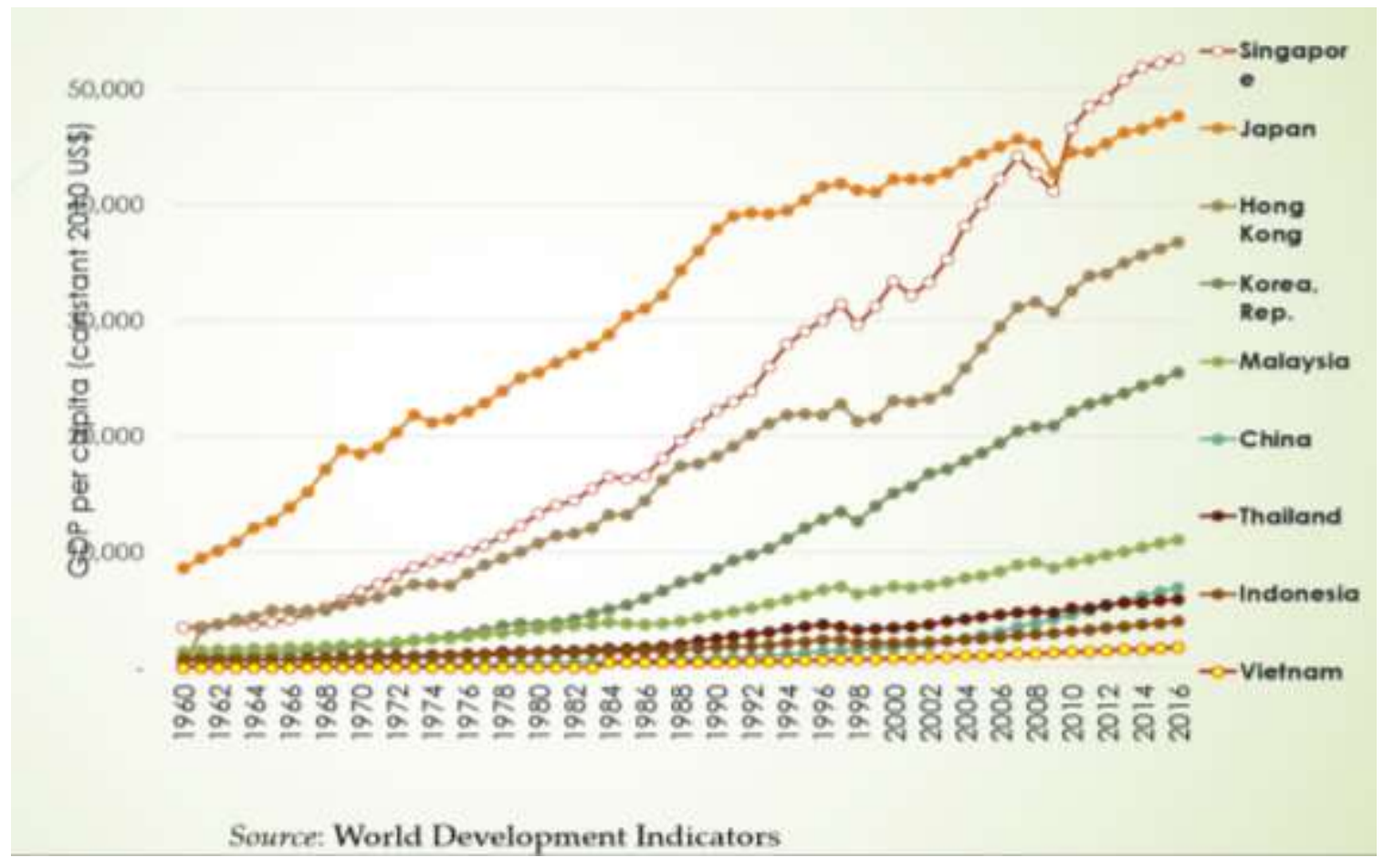


Tính dài hạn của xu thế suy giảm tốc độ tăng trương liên tục trong dài hạn gợi lên nguyên nhân thuộc về cơ cấu nội tại của nền kinh tế chư không phải là do nhũng sai sót chính sách nhất thời hay nhũng yếu kém nào đó của bộ máy điều hành. Tức là có vấn đề về sụ̣ suy yếu liên tục của động lục tăng trưởng mang tính hệ thống, gắn với sụ thay đổi phuơng thức phát triển của nền kinh tế chuyển đổi chứ không đơn thuần là những động lực cụ thể gắn với các giải pháp riêng biệt.

Nhận định này được bổ sung bằng một thực trạng phát triển "khác": Trong hơn 30 năm đổi mới (1986-2018), tính “sòng phẳng”, nền kinh tế nước ta mất 15 năm khủng hoảng và xủ lý khủng hoảng. Đó là các năm 1986-1990; 1997- 1999 và 20082015.

Trải qua các đợt thăng trầm, đến nay, sức khỏe của nền kinh tế vẫn chưa phục hồi đầy đủ. Những thành tựu đạt được của giai đoạn 1990-1996 nhờ động lực cải cách - mở cửa, của giai đoạn 2000-2007 (động lục là cải cách - hội nhập), đã bị xói mòn đáng kể trong thời kỳ khủng hoảng tài chính - tiền tệ Đông Á (1997-1999) và giai đoạn khủng hoảng hậu gia nhập WTO (2008-2015).

Tình hình đó phản ánh tính không vững chắc của quá trình tăng trưởng và phát triển, xu thế kém ổn định của các động lực phát triển (Hình 4)

Hình 4 - Tăng trưởng GDP hàng năm, tính theo quý, 2010-2018

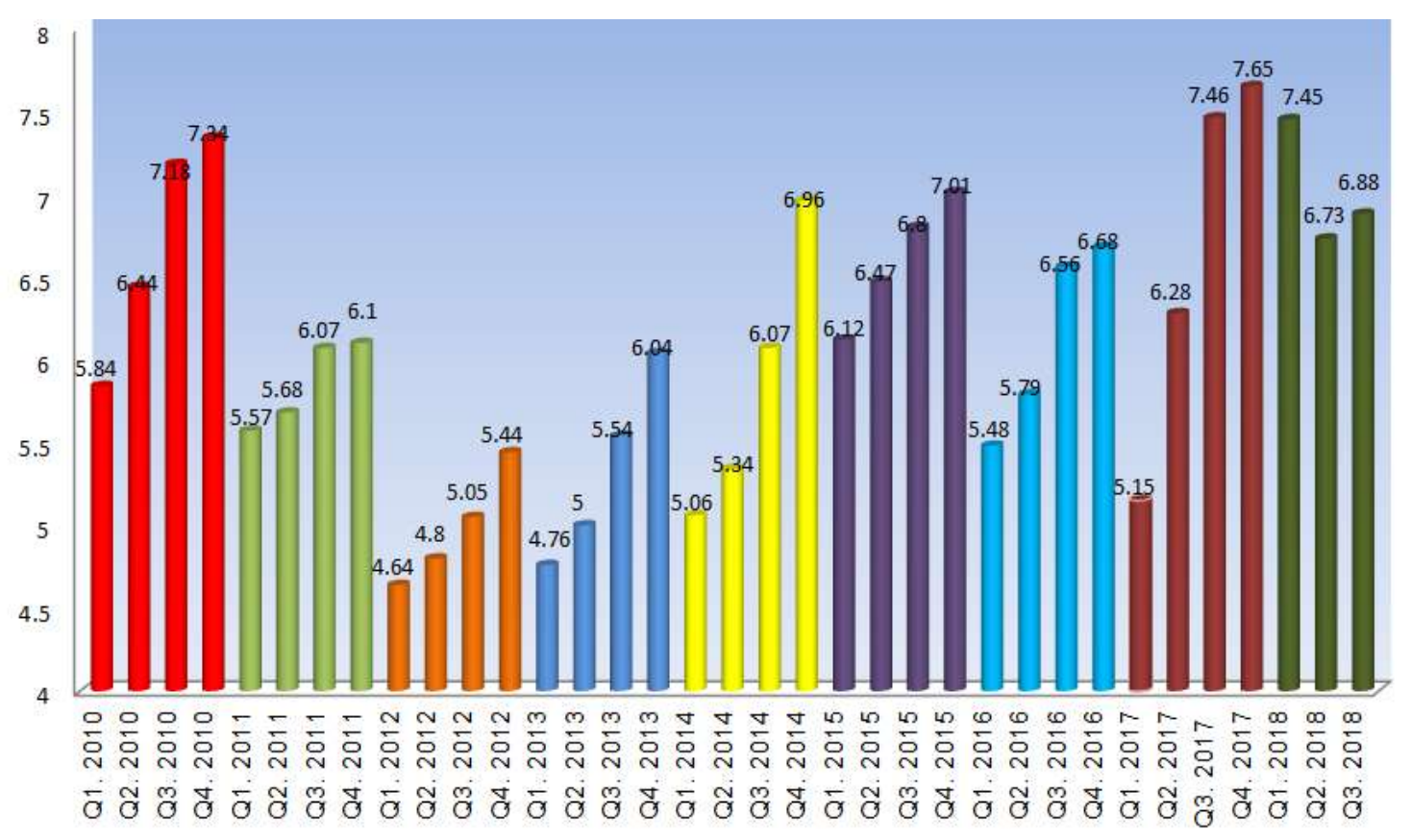


Hình dạng đồ thị cho thấy động thái tăng trưởng GDP lạ lùng: "tăng trưởng quý sau cao hơn quý trước" và luôn luôn hoàn thành kế hoạch tăng trưởng hàng năm.

Hình dạng đồ thị cũng phản ánh trạng thái khác thuờng của động lục phát triển: luôn nỗ lục "tối đa” để đạt thành tích tăng trưởng ngắn hạn, trong khi đồ thị 2 ở trên lại cho thấy "tình trạng có vấn đề” của tăng trưởng dài hạn.

Không nghi ngờ gì, “chủ nghĩa thành tích" là một thứ động lụcc tăng trưởng rất mạnh của nền kinh tế Việt Nam, ít nhất cũng là trong thời gian kéo dài cho đến năm 2017. Do là ngắn hạn nên động cơ tăng trưởng này không định hướng tới các mục tiêu - thành tích mang tính căn bản và dài hạn, như thay đổi trình độ cơ cấu ngành, nâng cấp công nghệ, tăng năng suất lao động và nâng cao chất lượng tăng trưởng. Về thực chất, động lực ngắn hạn này có tác động khác chiều (thúc đẩy mặt "số lượng” của tăng trưởng) và nghịch hướng (không khuyến khích, thậm chí cản trở, việc đạt các mục tiêu cơ cấu và chất lượng phát triển) với các nỗ lực đạt mục tiêu dài hạn. Nó gây nên tình trạng méo mó cơ chế và kìm giữ mô hình tăng trưởng kinh tế không còn phù hợp, thể hiện thành sự không nhất quán, thậm chí xung đột giữa động lực và mục tiêu phát triển kinh tế.

Thực trạng chung "có vấn đề" của động lực phát triển nói trên được thể hiện qua tình trạng chia cắt trong nền kinh tế - chia cắt doanh nghiệp, chia cắt lãnh thổ, phân biệt đối xử các thành phần, chủ thể, v.v.

\section{Cấu trúc chủ thể - thành phần kinh tế “dị thuờng”}

Hình 5 cho thấy chủ thể sản xuất nhiều GDP nhất là lực lượng non yếu nhất (kinh tế cá thể) và kém hiệu quả nhất (kinh tế nhà nước) trong khi khu vực đầu tư nước ngoài có xu thế "lấn át" khu vực nội địa².

\section{Hình 5: Cấu trúc nền kinh tế theo Thành phần - Chủ thể}

\footnotetext{
${ }^{2}$ Xu thế này dường như đi ngược lại đường lối "nội lực là quyết định, ngoại lực là quan trọng" của Đảng.
} 


\begin{tabular}{|c|c|c|c|c|c|c|}
\hline \multicolumn{3}{|c|}{$\begin{array}{l}\text { Thuế sp trù̀ trợ cấp } \\
\text { Kinh tế cá thể } \\
\text { Kinh tế tập thể } \\
100 \%\end{array}$} & & \multicolumn{3}{|c|}{$\begin{array}{l}\text { Khu vực có vốn đầu tư nước ngoài } \\
\text { Kinh tể tư nhân trong nước } \\
\text { Kinh tế Nhà nước }\end{array}$} \\
\hline & 12.1 & 11.3 & 11.4 & 11.6 & 11.5 & 11.5 \\
\hline $80 \%$ & 15.4 & 15.7 & 16.0 & 16.4 & 17.0 & 17.6 \\
\hline $60 \%$ & 32.7 & 32.8 & 32.5 & 32.5 & 32.3 & 31.6 \\
\hline $40 \%$ & $\begin{array}{l}7.0 \\
3.9\end{array}$ & $\begin{array}{l}7.2 \\
3.9\end{array}$ & $\begin{array}{l}7.3 \\
3.9\end{array}$ & $\begin{array}{l}7.3 \\
3.8\end{array}$ & $\begin{array}{l}7.4 \\
3.8\end{array}$ & $\begin{array}{l}7.8 \\
3.8\end{array}$ \\
\hline $20 \%$ & 28.9 & 29.1 & 28.9 & 28.4 & 28.0 & 27.8 \\
\hline & 2011 & 2012 & 2013 & 2014 & 2015 & 2016 \\
\hline
\end{tabular}

Nhiều công trình nghiên cứu cho thấy:

i) Sau 30 năm phát triển kinh tế thị truòng, khu vực doanh nghiệp tư nhân Việt Nam chỉ đóng góp chura đến $10 \%$ GDP;

ii) Mãi đến năm 2017, khu vực kinh tế tư nhân mới được Đảng và Nhà nước chính thức thù̀a nhận là "động lục phát triển quan trọng".

iii) trong 4 dộng lự tăng trưởng kinh tế, hiện nay, 3 động lục "nội" (DNNN, khu vục tư nhân Việt, khu vục hộ gia đình) bị suy yếu nghiêm trọng.

Tình trạng thiếu liên kêt, hợp tác phát triển giữa các thành phần, chủ thể kinh tế, được nhận diện qua khái niệm "nền kinh tế 2 trong 1 " (hàm ý sự chia cắt giữa khu vực nội địa và khu vực đầu tư nước ngoài). Khái niệm "lực lượng doanh nghiệp Việt Nam" thiếu nội hàm "chuẩn", chỉ chú trọng số lượng doanh nghiệp, ít quan tâm đến cấu trúc liên kết. Kết cục là tồn tại một khu vực doanh nghiệp manh mún, nhỏ bé, "chậm lớn, khó lớn, không muốn lớn”, thiếu trục liên kết, dẫn dắt phát triển - các tập đoàn kinh tế tư nhân mạnh (Hình 6).

\section{Hình 6: Cấu trúc "lực lượng" doanh nghiệp Việt Nam}




\begin{tabular}{|c|c|c|c|c|c|c|}
\hline & & & \multirow{2}{*}{\multicolumn{3}{|c|}{ Loại hình sở hữu }} & \multirow{3}{*}{$\begin{array}{l}\text { Tổng } \\
\text { cộng }\end{array}$} \\
\hline & & & & & & \\
\hline & & & $\begin{array}{l}\text { DN nhà } \\
\text { nước }\end{array}$ & $\begin{array}{l}\text { DN ngoài } \\
\text { nhà nước }\end{array}$ & DN FDI & \\
\hline \multirow{3}{*}{ 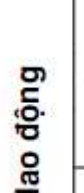 } & \multirow{3}{*}{ Siêu nhỏ } & Số lượng (DN) & 90 & 319.097 & 3.049 & 322.236 \\
\hline & & Tỷ lệ theo dòng (\%) & 0,03 & 99,03 & 0,95 & 72,82 \\
\hline & & Tỷ lệ theo cột (\%) & 3,17 & 74,61 & 25,53 & \\
\hline \multirow{9}{*}{ 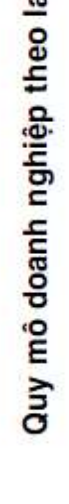 } & \multirow{3}{*}{ Nhỏ } & Số lượng (DN) & 1.139 & 97.105 & 5.509 & 103.753 \\
\hline & & Tỷ lệ theo dòng(\%) & 1,10 & 93,59 & 5,31 & 23,45 \\
\hline & & Tỷ lệ theo cột (\%) & 40,18 & 22,70 & 46,13 & \\
\hline & \multirow{3}{*}{ Vừa } & Số lượng (DN) & 407 & 6.304 & 934 & 7.685 \\
\hline & & Tỷ lệ theo dòng (\%) & 5,30 & 82.03 & 12,67 & 1,74 \\
\hline & & Tỷ lệ theo cột (\%) & 14,36 & 1,47 & 8,16 & \\
\hline & \multirow{3}{*}{ Lớn } & Số lượng (DN) & 1.199 & 5.203 & 2.410 & 8.812 \\
\hline & & Tỷ lệ theo dòng (\%) & 13,61 & 59,04 & 27,35 & 1,99 \\
\hline & & Tỷ lệ theo cột (\%) & 42,29 & 1,22 & 20,18 & \\
\hline \multirow{2}{*}{\multicolumn{2}{|c|}{ Tổng cộng }} & Số lượng (DN) & 2.835 & 427.709 & 11.942 & 442.486 \\
\hline & & Tỷ Iệ (\%) & 0,64 & 96,66 & 2,70 & 100,00 \\
\hline
\end{tabular}

Về không gian, tình trạng chia cắt giữa các nền kinh tế địa phương, giữa địa phương với kinh tế chung cả nước ${ }^{3}$ là một thực tế cần được phân tích và nhận diện rõ về mặt cơ chế. Tình trạng chia cắt đó cho thấy nền kinh tế thiếu động lực liên kết, do đó, không thể hội tụ, liên kết và cộng hưởng sức mạnh, tạo lan tỏa phát triển. Loại động lực phát triển quan trọng bậc nhất của kinh tế thị trường - cạnh tranh và liên kết phát triển - đã không được phát huy tác dụng đầy đủ trong nền kinh tế nước ta.

Tình trạng "phát triển dàn hàng ngang”, thiếu trọng tâm, trọng điểm, không có mũi nhọn - "đầu tàu” đúng nghĩa đã tồn tại trong nhiều năm. "Chiến lược quả mít" là thuật ngữ mô tả chính xác và sinh động trạng thái phát triển này.

Một bộ máy nhà nước điều hành kinh tế với biên chế cồng kềnh, luật lệ, chính sách, thủ tục chồng chéo, điều kiện kinh doanh phức tạp, một nền công vụ thiếu chuyên nghiệp, kém hiệu quả, chi phí giao dịch cao. Đây là một trong những nguyên nhân chủ yếu của tình trạng “không muốn lớn, khó lớn” của doanh nghiệp Việt Nam.

\subsection{Nguyên nhân suy giảm Động lục tăng truởng và phát triển.}

Trong giai đoạn đầu tiên của đổi mới, nỗ lực chuyển sang cơ chế kinh tế thị trường đã tạo ra động lực phát triển kép trong nền kinh tế: i) thay đổi cấu trúc sở hữu,

\footnotetext{
${ }^{3}$ Luận điểm "Việt Nam có 63 nền kinh tế (tỉnh) có cơ cấu giống nhau, tồn tại cạnh nhau nhưng không có mối liên hệ phát triển với nhau" phản ánh tư duy phát triển kinh tế "có vấn đề" của chúng ta.
} 
tạo động lực cạnh tranh thị trường; ii) điều tiết nhà nước, thực hiện chế độ phân phối vừa tuân thủ quy tắc thị trường (phân phối theo lao động và theo đóng góp tài sản), vừa bảo đảm công bằng xã hội (xóa đói giảm nghèo, chính sách xã hội) đã giúp nền kinh tế nhanh chóng thoát khỏi khủng hoảng, xác lập đà tăng trưởng và phát triển mới.

Nỗ lực mở cửa cũng đã mang lại cho nền kinh tế 2 loại động lực tăng trưởng mới mạnh mẽ. Đó là đầu tư trực tiếp nước ngoài $(\mathrm{FDI})$ và tăng trưởng xuất khẩu.

Tuy nhiên, sau giai đoạn khởi động đổi mới, xuất hiện nhiều yếu tố cản trở, làm suy yếu động lực phát triển kinh tế. Đó là:

- Không chú trọng phát triển các thị trường đầu vào của nền kinh tết đi liền với xu thế kiềm chế phát triển kinh tế tu nhân là một xu hướng thực tiễn kéo dài nhiều năm qua. Xu hướng này tự nó phản ánh "tình trạng có vấn đề” trong nhận thức lý luận đối với các khái niệm cơ bản của kinh tế thị trường và mối quan hệ của chúng với công thức phát triển sáng tạo của Việt Nam (định hướng XHCN). Tình trạng này đồng nghĩa với việc thiếu vắng môi trường cạnh tranh, thiếu vắng cạnh tranh lành mạnh. Mà trong nền kinh tế thị trường, cạnh tranh luôn là động lực cơ bản của phát triển.

Xu huớng kiềm chế, trì hoãn phát triển các thị truờng cũng giải thích tại sao công cuộc tái co cấu nền kinh tế và đổi mới mô hình tăng truởng trong 10 năm gần đây hầu nhu "dẫm chân tại chỗ", bất chấp nỗ lục to lớn của Nhà nước và của cả nền kinh tés.

Có cơ sở để khẳng định chính đây là nguồn gốc nhận thức và thục tiễn chủ yếu của xu hướng suy yếu động lục phát triển kinh tế ở nước ta trong giai đọ̣n vùua qua.

- Duy trì quá lâu co chế "phân biệt đối xủ", kéo theo đó là hệ thống xin-cho, nguồn gốc trực tiếp của tham nhũng - hối lộ và sự hình thành các nhóm lợi ích đối lập xung đột với lợi ích phát triển tổng thể là yếu tố chủ chốt làm triệt tiêu các động lục khuyến khích theo tinh thần "cạh tranh thị trường bình đẳng”. Sự rườm rà, phức

\footnotetext{
${ }^{4}$ Các thị trường đất đai, tiền tệ - tài chính, năng lượng, lao động.

${ }^{5}$ Có cơ sở để khẳng định rằng tình trạng kém phát triển của thị trường đất đai là một trong những nguyên nhân khách quan chủ yếu gây ra tình trạng chậm trễ và kém hiệu quả của công cuộc tái cơ cấu khu vực doanh nghiệp nhà nước trong 10 năm qua. Nó cũng góp phần giải thích nghịch lý tại
} 
tạp và kém hiệu quả của hệ thống quy định, điều kiện kinh doanh của Nhà nước đã làm tăng chi phí kinh doanh gấp bội, làm suy yếu sức cạnh tranh của doanh nghiệp.

- Một mô hình tăng truởng “dễ dãi” - dụa vào khai thác các nguồn tài nguyên sẵn có, vào nguồn lao động thiếu kỹ năng, vào việc "bơm” tín dụng rẻ đãa gây ra hệ lụy triệt tiêu động lục: đánh đổi tăng trưởng với môi trường, nền kinh tế tiền lương thấp, xu hướng lạm phát cao, v.v. Tích hợp những yếu tố "tiêu cực" đó tất yếu dẫn đến một nền kinh tế mang nặng tính đầu cơ. Không hề là tình cờ khi trong nhiều năm liền, số lượng doanh nghiệp bất động sản, các trung tâm, tư vấn môi giới kinh doanh bất động sản và chứng khoán thường chiếm tỷ lệ áp đảo trong tổng số doanh nghiệp đăng ký thành lập mới.

- Trong nhiều năm, mô hình tăng trưởng của Việt Nam được thiết kế theo định hướng khuyến khích nhập khẩu - cả đầu vào lẫn hàng tiêu dùng thông thường, không khuyến khích sản xuất nội địa và xuất khẩu. Cơ chế phân bổ ngân sách và phân bổ vốn đầu tư dựa trên nguyên tắc xin - cho, cho đến chính sách tỷ giá hối đoái, thuế xuất nhập khẩu - đã trở thành động lục mạnh thúc đẩy xu hướng lệ thuộc nhập khẩu đầu vào, khuyến khích phát triển các ngành gia công, lắp ráp, khai thác tài nguyên, kìm hãm phát triển các ngành công nghiệp hô trọ̆. Mô hình tăng trưởng đó không khuyến khích đổi mới - sáng tạo, triệt tiêu năng lực liên kết chuỗi và cạnh tranh lành mạnh trong cộng đồng doanh nghiệp Việt.

- Thiết kế và duy trì quá lâu hệ thống khuyến khích "ngược": các chính sách và biện pháp khuyến khích “chủ nghĩa thành tích”, nỗ lực đạt các thành tích số lượng ngắn hạn được chú trọng hơn là khuyến khích phát huy năng lực đổi mới - sáng tạo, nâng cao chất lượng và giá trị gia tăng cao ${ }^{6}$. Người tài ít được trọng dụng, cơ chế thu hút người tài quá thô sơ, chú trọng đến những "món lợi nhỏ” (tăng lương, thưởng, nhà ở) để hấp dẫn họ những không chú ý tạo điều kiện để họ phát huy năng lực.

Điển hình của hệ thống khuyến khích ngược là tình trạng vận dụng nguyên tắc “chọn người thắng” thay cho nguyên tắc "thưởng người thắng”.

\footnotetext{
${ }^{6}$ Có hiện tượng phổ biến trong nền kinh tế là cấp dưới phải xin cấp trên "cho phép" đổi mới. Phải "xin" để tránh rủi ro bị quy kết "chệch hướng", để được cấp nguồn lực thực hiện. Quy trình xét duyệt để được "đổi mới" lại rất phức tạp, không gắn với trách nhiệm cấp phê duyệt (cấp trên) nên thường gây nản lòng cho những ai muốn thực sự đổi mới, sẵn sàng chịu mạo hiểm để thúc đẩy phát triển.
} 
Cách chọn thầu không thông qua đấu thầu, hoặc tổ chức đấu thầu theo cách bố trí "quân xanh, quân đỏ”, lập "sân sau”, v.v. cũng là những biểu hiện cụ thể của cơ chế hoạt động này. Kết cục là nhiều chủ thể có năng lực thật sự lại bị loại ra khỏi cuộc đua.

Thực tế cho thấy, hệ thống chính sách "khuyến khích ngược" như vậy chứa đựng nhiều rủi ro cả đối với các chủ thể làm ăn chân chính lẫn các chủ thể "được chọn thắng”.

Với cách tạo động lực phát triển phi thị trường này mà ở Việt Nam, sau hơn 30 năm chuyển sang kinh tế thị trường, chỉ có rất ít doanh nghiệp tư nhân đủ sức vươn dậy thành tập đoàn kinh tế lớn, nhất là trong công nghiệp; hoặc giả có vươn lên thì nguy cơ rủi ro cũng rất cao. Trong khi đó, các Tập đoàn Kinh tế Nhà nước, được thúc đẩy phát triển theo cơ chế “chọn người thắng", cũng không thể lớn bình thường, làm ăn kém hiệu quả, độ rủi ro cao. Gần đây, hàng loạt Tập đoàn Kinh tế và Doanh nghiệp Nhà nước một thời "lừng lẫy" lâm vào tình trạng thiếu năng lực cạnh tranh, kinh doanh thua lỗ, đứng trước nguy cơ phá sản, giải thể; nhiều lãnh đạo "ưu tú" của khu vực này lâm vào cảnh lao lý, tù đày.

- Cơ chế, chính sách thu hút và sử dụng vốn FDI định hướng thiên lệch, mang tính phân biệt đối xử với lực lượng kinh tế bản địa, áp dụng trong thời gian quá dài, gây méo mó môi trường kinh doanh và những hậu quả phát triển chiến lược dài hạn.

Để thu hút đầu tư nước ngoài, hệ thống chính sách và giải pháp không chỉ dựa vào các "lợi thế sẵn có" (đi sau, vị trí địa - kinh tế, tài nguyên dồi dào, chi phí lao động rẻ, lao động chăm chỉ, môi trường chính trị - xã hội ổn định) mà còn đặc biệt nhấn mạnh các ưu đãi chính sách - ưu đãi thuế, ưu đãi tiếp cận đất đai, ưu đãi giá cả đầu vào (giá năng lượng, phí môi trường thấp), ... Những ưu đãi đó tạo ra tình trạng cạnh tranh bất bình đẳng giữa khu vực doanh nghiệp trong nước, đặc biệt là doanh nghiệp tư nhân, với các doanh nghiệp đầu tư nước ngoài và sự thiệt hại lợi ích phát triển quốc gia.

Cuộc cạnh tranh thu hút đầu tư nước ngoài giữa các địa phương diễn ra theo nguyên lý “cùng xuống đáy” vừa gây tổn hại lợi ích cho các địa phương, lại cũng làm cho các doanh nghiệp trong nước, vốn đang yếu, dễ rơi vào thế bất lợi, chịu thiệt thòi nhiều mặt, suy giảm động lực phát triển. 
Đây là một trong những nguyên nhân quan trọng giải thích tại sao đa số doanh nghiệp nước ngoài đầu tư ở Việt Nam sử dụng công nghệ không cao, có nguy cơ gây ô nhiễm môi trường lớn, trả lương thấp và không muốn liên kết phát triển với các doanh nghiệp nội địa. Một bộ phận lớn doanh nghiệp nước ngoài, có thể lên tới hơn $60 \%$, khai lỗ liên tục nhiều năm nhưng lại không ngừng mở rộng kinh doanh. Loại động cơ khuyến khích "ngược" này, thật trớ trêu, lại giúp khu vực đầu tư nước ngoài trở thành khu vực động lực phát triển ngày càng quan trọng trong nền kinh tế nước ta.

\section{Bối cảnh mói, yêu cầu mới và giải pháp tăng cường động lực phát triển cho giai đoạn mới.}

\subsection{Bối cảnh thời đại và các yêu cầu mới đối với hệ thống động lục phát triển.}

Thế giới đang bước vào một thời đại phát triển mới, khác biệt căn bản về trình độ, cấu trúc và logic phát triển với các giai đoạn trước. Bước chuyển thời đại lần này, do vậy, cũng khác biệt hoàn toàn so với các bước chuyển trước đây.

Có thể định hình thời đại đang được định hình bằng 4 nội dung cơ bản:

Thứ nhất, xu hướng toàn cầu hóa vẫn tiếp tục mạnh mẽ, nhưng với những giải pháp khác biệt và mang tính xung đột (xu thế "bảo hộ"). Trong thời đại này, hội nhập và cạnh tranh quốc tế vẫn là môi trường và là một trong nhũng động lục cơ bản của phát triển.

Thứ hai, $\mathrm{CMCN} 4.0$ là định hướng chủ yếu để loài người tiến vào nền kinh tế công nghệ cao với tư cách là sự tích hợp của nền kinh tế vật thể - công nghệ cao với nền kinh tế số. Công nghệ cao và kinh tế số là nền tảng phát triển mới của loài người; còn quá trình $\mathrm{CMCN} 4.0$ lại mang tính đột phá mạnh mẽ, với tốc độ cao chưa từng thấy. Trên cả hai góc độ, đổi mói - sáng tạo đều đóng vai trò là động lục phát triển mạnh nhất và có tiềm năng vô tận của thế giới trong giai đoạn tới ${ }^{7}$.

Thứ ba, cục diện phát triển thế giới thay đổi, xung đột toàn cầu với trục chi phối là quan hệ Hoa Kỳ - Trung Quốc có xu hướng gia tăng. Xung đột giữa Hoa Kỳ và Trung Quốc - hai cường quốc hàng đầu thế giới, hai đối tác kinh tế - chính trị quan

\footnotetext{
${ }^{7}$ Xu thế này gắn với tình huống lợi thế so sánh "lao động tiền lương thấp" và khai thác tài nguyên của Việt Nam đang mất đi. Cấu trúc nguồn lực và động lực phát triển đang thay đổi sâu sắc chưa từng thấy.
} 
trọng bậc nhất của Việt Nam, đang tạo ra những cơ hội và thách thức phát triển mang tầm lịch sử - thời đại lớn chưa từng thấy cho toàn thế giới ${ }^{8}$ và Việt Nam.

Thứ tư, biến đổi khí hậu mà Việt Nam là một trong những nước chịu tác động mạnh nhất, đặt ra những yêu cầu và đòi hỏi mới về năng lực và giải pháp ứng phó.

Việc định hình thời đại bằng 4 nội dung nói trên chưa thể bao quát hết các $x u$ thế và quá trình toàn cầu đang và sẽ diễn ra, song, tạm đủ để khẳng định rằng cần có cách tiếp cận mới đến vấn đề phát triển. Yêu cầu này thực sự là gay gắt, cấp bách khi các quá trình và xu hướng nêu trên đều đang diễn ra với tốc độ cao và tính bất thường chưa từng thấy.

Hàm ý của nhận định này là: cải tiến, nâng cấp, nâng cao hiệu quả của các nguồn lực và động lực truyền thống là không đủ. Phải tích cực định hướng tìm kiếm cả những nguồn lực và động lực phát triển mới, theo những cách mới.

Những yếu tố định hình thời đại nêu trên gợi ý cách tiếp cận mới đến động lực phát triển.

- Các động lực phát triển gắn với quá trình chuyển đổi kinh tế sẽ tiếp tục phát huy tác dụng trong giai đoạn tới.

- Nền kinh tế thời đại 4.0 đòi hỏi Việt Nam không thể chỉ dừng lại ở việc khắc phục các “điểm nghẽn" phát triển và tăng trưởng mà nền kinh tế đang lâm vào. Là nền kinh tế có độ mở cửa và hội nhập cao, Việt Nam phải tạo lập nền tảng cấu trúc mới và các động lực phát triển hiện đại tương thích với thời đại CMCN4.0.

Thứ nhất, cuộc $\mathrm{CMCN} 4.0$ đang tạo ra một cấu trúc phát triển khác biệt về logic: trên nền tảng công nghệ cao và số hóa. Loài người được cung cấp những công cụ phát triển rất mới, để xây dựng một hệ thống kinh tế mới, tích hợp giữa nền kinh tế vật thể (truyền thống) và nền kinh tế số. Nền kinh tế này vận hành với những nguồn lực mới, có cấu trúc liên kết và cơ chế vận hành mới, định hướng thỏa mãn một cơ cấu nhu cầu mới. Để xây dựng và vận hành nền kinh tế đó, cần có những năng lực mới và cả những động lực mới.

\footnotetext{
${ }^{8}$ Xu hướng dịch chuyển các chuỗi sản xuất ra khỏi Trung Quốc, nguy cơ suy giảm tăng trưởng và bất ổn kinh tế toàn cầu dưới tác động của cuộc xung đột Hoa Kỳ - Trung Quốc đang đóng vai trò là những động lực phát triển kinh tế mạnh mẽ bậc nhất theo cả hai chiều thuận và nghịch của thế giới hiện đại.
} 
Thứ hai, việc tham gia hội nhập kinh tế quốc tế bằng các FTA thế hệ mới hàm nghĩa việc tuân thủ các đòi hỏi thể chế kinh tế, các chuẩn mực và quy định kỹ thuật của sản phẩm dịch vụ ở trình độ rất cao. Trong trường hợp này, hội nhập quốc tế không chỉ mang đến những cơ hội to lớn, mà còn tạo ra những áp lực phát triển chưa từng thấy. Cả cơ hội lẫn áp lực phát triển đều trở thành động lực cải cách, nâng cao năng suất lao động, thúc đẩy nền kinh tế vươn nhanh lên đẳng cấp phát triển mới.

Việc chuyển hóa áp lục phát triển thành động lục cải cách phải được coi là một cách tiếp cận phát triển mới trong thời đại mở cửa - hội nhập quốc tế của Việt Nam.

\subsection{Cách tiếp cận và định hướng giải pháp mới}

\subsubsection{Cách tiếp cận:}

Thứ nhất, tuân thủ nguyên lý của Chủ nghĩa Mác - Lê nin: xây dựng quan hệ sản xuất phù hợ, mở đuờng cho lực luợng sản xuất phát triển trên cơ sở đổi mới để tăng tính chu động tiên phong của hệ thống kiến trúc thương tầng, đặc biệt là thuợng tầng chính trị. Tại thời điểm hiện nay, tính tiên phong đổi mới của hệ thống chính trị đang là điều kiện tiên quyết để cải cách thể chế kinh tế, từ đó, kiến tạo hệ thống động lực phát triển mới để thúc đẩy cải cách và phát triển.

Thứ hai, phát triển đồng bộ các loại thị trường, đặc biệt quan tâm phát triển các thị trưòng nguồn lục đầu vào, nhất là thị truờng đất đai, là nội dung quan trọng nhất để tạo động lực phát triển của nền kinh tế trong giai đoạn tới.

Thứ ba, xây dựng nhà nước kiến tạo phát triển theo tinh thần phục vụ thị trường, phục vụ doanh nghiệp, thiết kế một thể chế quản trị phát triển hiện đại, phù hợp với các cam kết hội nhập.

Thứ tư, tuân thủ nguyên tắc "nội lực là quyết định, ngoại lực là quan trọng" trong việc phát triển lực lượng doanh nghiệp Việt Nam và triển khai chiến lược thu hút và sử dụng FDI trong giai đoạn tới.

Thứ năm, thực hiện các cam kết hội nhập quốc tế là áp lực - động lực cải cách và phát triển mạnh mẽ bậc nhất. 
Thứ sáu, tận dụng tối đa lợi thế đi sau, nỗ lực xây dựng thể chế tốt, khuyến khích đổi mới sáng tạo, coi khoa học công nghệ và trí tuệ con người là động lực phát triển quan trọng nhất của giai đoạn tới.

\subsubsection{Các định hướng giải pháp}

- Xây dựng chiến lược phát triển đồng bộ các thị trường đầu vào. Đặc biệt chú ý chiến lược phát triển thị trường đất đai theo tinh thần thừa nhận chế độ đa sở hữu. Xây dựng hệ thống pháp luật thừa nhận, tôn trọng và bảo vệ quyền tài sản của các chủ thể kinh tế. Coi việc phát triển các thị trường đầu vào là nền tảng để tái cơ cấu kinh tế và đổi mới mô hình tăng trưởng thành công.

- Xây dựng và triển khai Chương trình quốc gia "Phát triển lực lượng doanh nghiệp Việt Nam" theo đúng tinh thần thị trường: các chủ thể bình đẳng về tư cách, khác biệt về chức năng, được khuyến khích phát triển theo nguyên tắc "khuyến khích người thắng”. Đặc biệt quan tâm thúc đẩy xây dựng các chuỗi sản xuất Việt Nam, tạo điều kiện phát triển các tập đoàn kinh tế mạnh của Việt Nam thành lực lượng dẫn dắt quá trình hình thành và phát triển chuỗi, trụ cột là các tập đoàn kinh tế tư nhân.

- Tích cực cải cách nhà nước với hai nội dung lớn: i) xây dựng một nhà nước phục vụ phát triển; ii) xây dựng một nhà nước thông minh, trong đó, một nội hàm quan trọng là xây dựng "Chính phủ Số” và "đô thị thông minh".

Các biện pháp cụ thể:

+ Xây dựng bộ máy nhà nước theo nguyên tắc i) "tổ chức theo chức năng"; ii) tính chuyên nghiệp công vụ (tuyển chọn cán bộ và trách nhiệm công việc);

+ Cải cách chế độ lương trong khu vực nhà nước theo nguyên tắc i) tiền tệ hóa hoàn toàn tiền lương; ii) trả lương theo chức năng; iii) trả lương theo hợp đồng công việc (theo mức độ hoàn thành công việc cam kết);

- Thực hiện chiến lược thu hút và sử dụng đầu tư nước ngoài mới, theo nguyên tắc "hạn chế ưu đãi, quan tâm xây dựng thể chế tốt", tạo thuận lợi tối đa để hình thành và phát triển các chuỗi sản xuất với sự tham gia tích cực của các nhà đầu tư chiến lược nước ngoài. 
- Thiết kế hệ thống chính sách nhất quán và định hướng dài hạn, hạn chế nhập khẩu đầu vào phục vụ gia công lắp ráp, gây ô nhiễm môi trường (công nghệ thấp và giá trị gia tăng thấp) và xu hướng thúc đẩy các hoạt động đầu cơ.

- Từ bỏ cơ chế phân phối vốn theo kiểu chia đều, xin - cho, tập trung phát triển các cực tăng trưởng và các trung tâm phát triển đủ tầm và sức cạnh tranh quốc tế. Nhanh chóng phát triển các đô thị thông minh, trước tiên là các đô thị "đầu tàu" (TP. Hà Nội, TP. Hồ Chí Minh, Hải Phòng, Đà Nẵng, Cần Thơ, Nha Trang, Vinh, Buôn Mê Thuột).

- Nhà nước tích cực hỗ trợ xây dựng các Trung tâm đổi mới - sáng tạo quốc gia, tạo các đầu mối thức đẩy công cuộc "khởi nghiệp quốc gia" theo tinh thần đổi mới - sáng tạo đúng nghĩa. Có chính sách hỗ trợ đặc biệt các doanh nghiệp khoa học công nghệ, đổi mới -sáng tạo, để khoa học - công nghệ trở thành động lực phát triển mạnh mẽ nhất trong giai đoạn tới.

\section{Kết luận}

Kinh tế Việt Nam đang ở vào một thời điểm mang tính bước ngoặt. Những động lực mạnh mẽ thúc đẩy nền kinh tế chuyển đổi phát triển được khơi dậy nhờ công cuộc đổi mới đã suy giảm tác động. Để nền kinh tế khôi phục đà tăng trưởng, vấn đề đặt ra không phải là chỉnh sửa, cải tiến, nâng cấp hệ thống động lực cũ. Nghĩa là Việt Nam không thể giải quyết vấn đề "tụt hậu phát triển" - đúng hơn là "tụt hậu phát triển xa hơn” bằng cách tiếp tục duy trì hệ thống động lực cũ. Thực tiễn 10 năm Tái Cơ cấu Kinh tế và Đổi mới mô hình tăng trưởng chứng tỏ điều đó.

Phương cách giải quyết vấn đề là thay đổi hệ thống động lực tăng trưởng và phát triển.

Nhưng đó chỉ là một mặt của nhiệm vụ phát triển đang đặt ra cho Việt Nam, xuất phát từ chính nhu cầu nội tại của nền kinh tế.

Thế giới đang thay đổi sâu sắc.

Thay đổi cấu trúc dưới tác động của cuộc Cách mạng Công nghiệp 4.0 có sức mạnh "đảo lộn logic phát triển" mà loài người chưa từng được thấy trong ba cuộc Cách mạng Công nghiệp trước. 
Thay đổi tương quan sức mạnh và cục diện phát triển toàn cầu - với sự trỗi dậy mạnh mẽ chưa từng thấy khi Trung Quốc và Ân Độ cùng một loạt nền kinh tế đi sau. Xung đột Mỹ - Trung Quốc là hệ quả không thể tránh khỏi của việc phản ứng lại sự trỗi dậy đó. Toàn cầu hóa "biến dạng" kết hợp với sự trỗi dậy của chủ nghĩa bảo hộ.

Các yếu tố nói trên cộng hưởng lại, tạo thành một thời đại phát triển mới - khác về cấu trúc và logic phát triển.

Việt Nam là nền kinh tế có độ mở cửa cao, nghĩa là "tự nhiên" bước vào thời đại mới đó. Cơ hội hoàn toàn mới, thách thức hoàn toàn mới. Để "bước vào" mà không bị "kéo lê" theo thời đại, Việt Nam cần một hệ động lực phát triển mới không chỉ là hệ động lực cũ "được đổi mới”. Chỉ đổi mới hệ động lực cũ hiện giờ là không đủ, nghĩa là lại đẩy nền kinh tế vào thế tụt hậu xa hơn.

Nhiệm vụ đặt ra cho nền kinh tế tại thời điểm không mới về tên gọi, nhưng đầy thách thức: Đổi mới hệ động lực phát triển ở một tầm mới so với cách đây 30 năm.

\section{DANH MỤC TÀI LIỆU THAM KHẢO}

\section{Tiếng Việt}

1. CIEM, VIE, VEPR, VCCI. Từ Nhà nước Điều hành sang Nhà nước Kiến tạo Phát triển. NXB. Tri Thức, 2016.

2. Đảng Cộng sản Việt Nam. Văn kiện Đại hội các kỳ.

3. Đào Quang Thu (2013). Đầu tu trục tiếp nước ngoài tại Việt Vam: 25 năm thu hút và phát triển, Kỷ yếu Hội nghị 25 năm FDI tại Việt Nam, Bộ Kế hoạch và Đầu tư.

4. Đinh Tuấn Minh, Phạm Thể Anh (chủ biên), (2014). Báo cáo phát triển nền kinh tế thị truờng Việt Nam 2014, NXB Tri thức, Hà Nội.

5. Hoàng Văn Hải (Chủ biên). 2012. Tinh thần Doanh nghiệp Việt Nam trong Hội nhập. NXB Đại học Quốc gia Hà Nội.

6. Ngân hàng Thế giới (2014-2018). Điểm lại: Cập nhật tình hình phát triển kinh tế Việt Nam.

7. Ngô Tuấn Nghĩa (2016). "Tiếp tục hoàn thiện thể chế sở hữu đáp ứng yêu cầu phát triển kinh tế thị trường định hướng XHCN ở Việt Nam”, Tạp chí Nghiên cúu kinh tế, (9/2016), $3-8$.

8. Nguyễn Kế Tuấn (chủ biên, 2010). Vấn đề sở hũu trong nền kinh tế thị truờng định huớng xã hội chủ nghĩa ở Việt Nam, NXB Chính trị quốc gia, Hà Nội. 
9. Nguyễn Kim Bảo (2003). Thể chế kinh tế thị truờng XHCN đặc sắc Trung Quốc (Một số đột phá mói về lý luận và thực tiễn tù Đại hội XV ĐCS Trung Quốc đến nay), NXB KHXH.

10. Nguyễn Trọng Hoài và Huỳnh Thanh Điền (2011). Phát triển kinh tế tư nhân: Tiếp cận các giải pháp giảm thiểu tác động lấn át và nâng cao tác động hỗ trợ, Tạp chí Phát triển Kinh tế, (3/2011): 2-7.

11. Nhóm Ngân hàng Thế giới, Bộ Kế hoạch và Đầu tư. Việt Nam 2035. Hướng tới Thịnh vượng, Sáng tạo, Công bằng và Dân chủ. NXB. Hồng Đức, 2016.

12. Phạm Minh Chính và Vương Quân Hoàng (2009). Kinh tế Việt Nam: Thăng trầm và đột phá, NXB. Tri Thức.

13. Trần Đình Thiên (chủ biên, 2014). Báo cáo Kinh tế Việt Nam, các năm 2013, 2014, 2015, 2016. NXB. Khoa học Xã Hội

14. Vũ Thành Tự Anh (2014). Gia nhập WTO và cải cách DNNN ở Việt Nam. Trong "Báo cáo kinh tế vĩ mô 2014- cải cách thể chế kinh tế: chìa khóa cho tái cơ cấu”. NXB Tri thức, Hà Nội.

15.D. Yergin, J. Stanislaw. Những đỉnh cao chỉ huy. NXB. Thế giới, 2018 (Tái bản).

\section{Tiếng Anh}

16. Chang-Tai Hsieh, Zheng (Michael) Song. (2015): Grasp the Large, Let Go of the Small: The Transformation of the State Sector in China, NBER Working Paper No. 21006 Issued in March 2015 (http://www.nber.org/papers/w21006)

17. John Schaus (2015): Private sector development in China's Foreign policy. CSIS. (https://csisprod.s3.amazonaws.com/s3fspublic/legacy_files/files/publication/1505

18. Newman et al. (2013). Technology transfers, foreign investment and productivity spillovers: evidence from Vietnam, Ciem.

19. Ohno K. (2010). Avoiding the Middle Income Trap: Renovating Industrial Policy Formulation in Vietnam, Vietnam Development Forum (VDF), Hanoi.

20. Perkins et al. (2013). Unplugging Institutional Bottlenecks to Restore Growth, A Policy Discussion Paper Prepared for the Vietnam Executive Leadership Program (VELP).

21. Su Dinh Thanh (2014). Government size and economic growth in Vietnam: A panel analysis, retrieved from http://ssrn.com/abstract $=2437242$. 